\author{
Institute of Parasitology \\ of the Vetsuisse Faculty University of Zurich
}

Director: Prof. Dr. med. vet. Peter Deplazes

Work under the academic supervision of

Prof. Dr. med. vet. Peter Deplazes

Prof. Dr. med. vet. Paul Torgerson

\title{
Antibody kinetics and exposure to Toxoplasma gondii in cats: a seroepidemiological
} study

\section{Inaugural Thesis}

to obtain the title of Doctor from the

Vetsuisse Faculty University of Zurich

submitted by

\section{Nora Schreiber}

\author{
Veterinarian \\ of Frankfurt, Germany
}

Approved at the request of

Prof. Dr. med. vet. Peter Deplazes, supervisor 



\section{Table of Content}

Content

Summary (English)

Summary (German)

Accepted manuscript

Abstract

Highlights

Introduction

Material and Methods

Results

Discussion

References

Figure captions

Table Legends

Figures

Acknowledgments

Curriculum Vitae

\section{Page number}

5

6

7

7

8

9

11

12

16

21

22

23 


\author{
Vetsuisse Faculty University of Zurich (2020) \\ Nora Schreiber \\ Institute of Parasitology, parasito@vetparas.uzh.ch
}

Antibody kinetics and exposure to Toxoplasma gondii in cats: a seroepidemiological study

\begin{abstract}
Domestic cats are unique definitive hosts for Toxoplasma gondii, the agent of an important global zoonosis and one of the most intensively studied coccidia. Nevertheless, many aspects in particular of its intestinal development and epidemiology are yet unknown.

This study showed that antibody kinetics in three cats orally inoculated with tissue cysts, shedding oocysts, did not differ significantly from those of three cats inoculated with sporulated oocysts without detectable oocyst excretion, suggesting extraintestinal parasite invasion and exposure to tachyzoites at an early stage of infection after inoculation with any of both parasite stages. Analysis of serial serum samples from 65 naturally infected client-owned cats documented a persisting long-term humoral immune response over months to years. Of the 1,757 client-owned cats, presented to veterinarians in Switzerland, $42.4 \%$ had a positive antibody response to $T$. gondii with the ELISA. This was higher $(56.3 \%)$ in cats with outside access than in those without $(22.1 \%)$. In the risk factor analysis, the factors age $(\mathrm{p}<0.0001)$, gender (male: $p=0.046)$, and outside access $(\mathrm{p}<0.0001)$ were independently associated with significantly higher ELISA values.
\end{abstract}

In conclusion the results of this study not only provide a basis for future surveillance but are of importance for future interpretation of seroepidemiological studies.

Keywords: Toxoplasma gondii, seroprevalence, cat, risk factors, zoonosis. 
Vetsuisse Fakultät Universität Zürich (2020)

Nora Schreiber

Institut für Parasitologie, parasito@vetparas.uzh.ch

Antibody kinetics and exposure to Toxoplasma gondii in cats: a seroepidemiological study

Zusammenfassung

Hauskatzen sind einzigartige Endwirte von Toxoplasma gondii, dem Erreger einer wichtigen globalen Zoonose und eine der am intensivsten untersuchtesten Kokzidien. Dennoch sind viele Aspekte, insbesondere der intestinalen Entwicklung und Epidemiologie, noch unerforscht.

In dieser Studie wurde gezeigt, dass die Antikörperkinetik bei drei Katzen, die oral mit Gewebezysten inokuliert wurden und Oozysten ausschieden, sich nicht signifikant unterscheidet von der bei drei Katzen, die mit sporulierten Oozysten inokuliert wurden, ohne nachweisbare Oozystenausscheidung. Dies weist auf eine extraintestinale Parasiteninvasion und die Exposition gegenüber Tachyzoiten in einem frühen Stadium der Infektion hin. Die Analyse von seriellen Seren von 65 natürlich infizierten Katzen dokumentiert eine persistierende humorale Langzeitimmunantwort über Monate bis Jahre. Von den 1.757 Katzen, die Veterinären/innen in der Schweiz vorgestellt wurden, zeigten 42,4\% spezifische Antikörper gegen T. gondii im ELISA. Die Seroprävalenz war bei Katzen mit Freigang höher (56,3\%) als bei Wohnungskatzen $(22,1 \%)$. In der Risikofakorenanalyse war Alter $(\mathrm{p}<0,0001)$, Geschlecht (männlich: $\mathrm{p}=0,046)$ und Freigang $(\mathrm{p}<0,0001)$ unabhängig voneinander mit signifikant höheren ELISA-Werten assoziiert.

Zusammenfassend stellen die Ergebnisse dieser Studie nicht nur eine Grundlage für die zukünftige Überwachung dar, sondern sie sind auch wichtig für die künftige Interpretation seroepidemiologischer Studien.

Stichworte: Toxoplasma gondii, Seroprävalenz, Katze, Risikofaktoren, Zoonose. 
Antibody kinetics and exposure to Toxoplasma gondii in cats: a seroepidemiological study

\section{Nora Schreiber a, Walter Basso ${ }^{\text {a,b }}$, Barbara Riond c, Barbara Willi d, Paul Torgerson e,1,", Peter Deplazes ${ }^{\text {a, }, \text {,* }}$}

${ }^{a}$ Institute of Parasitology, University of Zurich, Vetsuisse Faculty, Winterthurerstrasse 266a, CH-8057, Zurich, Switzerland

b Present address: Institute of Parasitology, University of Bern, Vetsuisse Faculty, Länggassstrasse 122, 3001, Bern, Switzerland

${ }^{\mathrm{c}}$ Clinical Laboratory, University of Zurich, Vetsuisse Faculty, Winterthurerstrasse 260, CH8057, Zurich, Switzerland

${ }^{d}$ Clinic for Small Animal Internal Medicine, University of Zurich, Vetsuisse Faculty, Winterthurerstrasse 260, CH-8057, Zurich, Switzerland

${ }^{\mathrm{e}}$ Section of Epidemiology, University of Zurich, Vetsuisse Faculty, Winterthurerstrasse 270, CH-8057, Zurich, Switzerland

${ }^{1}$ These authors contributed equally.

* Corresponding authors. Institute of Parasitology, University of Zurich, Vetsuisse Faculty, Winterthurerstrasse 266a, CH-8057, Zurich, Switzerland and Section of Epidemiology, University of Zurich, Vetsuisse Faculty, Winterthurerstrasse 270, CH-8057, Zurich, Switzerland,

E-mail addresses: deplazesp@access.uzh.ch (P. Deplazes) and paul.torgerson@access.uzh.ch (P. Torgerson), Tel.: +41 446358501. 


\begin{abstract}
Domestic cats are the most important definitive hosts for Toxoplasma gondii, the agent of an important global zoonosis. Serial sera from cats orally inoculated either with $T$. gondii tissue cysts $(n=3)$ or sporulated oocysts $(n=3)$ and from 65 client-owned cats, plus sera from 1,757 client-owned cats presented to veterinarians in Switzerland were analyzed for an antibody response to $T$. gondii by ELISA. Risk factors for seropositivity and prevalence were estimated with a generalized linear and beta regression model. The first model examined the association of an $\mathrm{OD}_{405}$ value as the dependent variable, with gender, age, and outside access as possible independent variables. In the second model, we first analyzed the data assuming a bimodal distribution representing two overlapping distributions of $\mathrm{OD}_{405}$ values from positive and negative cats, enabling the assignment of a probability of true infection status to each cat. Mean probabilities of true infection status across groups represent an estimate of true prevalence. These probabilities were then regressed against age, gender and outside access. Antibody kinetics in cats orally inoculated with tissue cysts, shedding oocysts, did not differ significantly from those of cats inoculated with sporulated oocysts without detectable oocyst excretion, suggesting extraintestinal parasite invasion and exposure to tachyzoites in both situations at an early stage of infection. Analysis of serial serum samples suggested a persisting long-term humoral immune response. Of the client-owned cats, $42.4 \%$ (95\% confidence interval (CI): 40.1-44.6) had a positive true infection status. This was higher (56.3\% (95\% CI: 53.2-59.6)) in cats with outside access than in those without (22.1\% (95\% CI: 18.9-25.4)). In the first model, the factors age $(P<0.0001)$, gender (male: $P=0.046)$, and outside access $(P<0.0001)$ were independently associated with significantly higher $\mathrm{OD}_{405}$ values. In the second model, the probability of having a positive true infection status increased with age $(P<0.0001)$, was higher with outside access $(P<0.0001)$ and in outdoor male cats $(P=0.0006)$.
\end{abstract}

\title{
Keywords:
}

- Toxoplasma gondii

- Seroprevalence

- Switzerland

- Cat

- Risk factors

- Zoonosis

\section{Highlights:}

- Antibody kinetics were similar in cats inoculated with Toxoplasma gondii tissue cysts and oocysts.

- Naturally infected cats elicited a persisting humoral immune response against $T$. gondii.

- The Swiss cat population had a positive true T. gondii infection status of $42.4 \%$.

- Male gender, age and outside access were associated with a higher risk for seropositivity. 


\section{Introduction}

Toxoplasma gondii is a zoonotic protozoan parasite infecting a large variety of mammals and birds with a global distribution (Dubey and Beattie, 1988; Tenter et al., 2000). Domestic cats and other Felidae are the unique definitive hosts for $T$. gondii, as the enteroepithelial life cycle and production of oocysts, which are shed with feces, can be only completed in the intestinal tract of these animal species (Frenkel et al., 1970; Tenter et al., 2000). Cats are primarily infected by predation of small mammals and birds, or by ingestion of insufficiently cooked meat containing Toxoplasma cysts with bradyzoites. Other possible but epidemiologically less important ways of infection for cats are the uptake of sporulated oocysts from the contaminated environment, ingestion of tachyzoites via milk and intrauterine transmission (Frenkel et al., 1970; Dubey and Beattie, 1988; Dubey et al., 1996; Tenter et al., 2000; Powell et al., 2001). Experimentally, the majority of previously naïve cats shed oocysts 3 - 10 days after ingesting bradyzoites (Dubey and Frenkel, 1976). Parasite biology after sporozoite invasion has been less investigated, but several studies reported oocyst excretion in approximately $20 \%$ of cats infected with oocysts, with prolongated prepatent periods of more than 18 days (Wallace, 1973; Dubey, 2002). Freshly excreted oocysts sporulate within 1 - 21 days in the environment depending on oxygen exposure, temperature, humidity, as well as other factors (Dubey et al., 1970). Sporulated oocysts containing sporozoites have a high tenacity and can be infectious for many years under optimal conditions (Frenkel et al., 1975). Furthermore, as in intermediate hosts, cats can harbor extraintestinal $T$. gondii stages. During the acute phase of infection $T$. gondii-tachyzoites undergo rapid asexual multiplication in potentially all types of nucleated cells until the host's immune response and other factors attenuate the replication, driving the formation of bradyzoites-containing cysts, persisting in asymptomatic cats over years (Dubey and Beattie, 1988; Tenter et al., 2000; Weiss and Dubey, 2009). During the course of natural infections, protective long-term immunity against tachyzoite pathology is thought to be maintained through continuous exposure to bradyzoites and reconverted tachyzoites derived from the persistent infection (Skariah et al., 2010). In cats, intestinal $T$. gondii infections are usually asymptomatic or may cause, especially in young cats, mild, self-limiting diarrhea. The extraintestinal infection in cats is mainly asymptomatic but can sometimes result in ocular, pulmonary, central nervous, pancreatic, or hepatic disease and death (Dubey and Carpenter, 1993).

Based on the assumption of a long-term humoral immune response in cats, serological testing has been performed to analyze the specific $T$. gondii seroprevalence in cat populations worldwide. Multiple assays have been established, including the Sabin-Feldman dye test, indirect fluorescent antibody test (IFAT), latex agglutination test (LAT), modified agglutination test (MAT), immunoblot, and ELISA to detect specific IgM, IgG, and IgA antibodies against tachyzoite antigens or antigen fractions (Lappin, 2010). ELISAs targeting antibodies directed against the purified tachyzoite surface antigens were found to be more specific than tests using total tachyzoite antigen suspensions in pigs (Pardini et al., 2012). Furthermore, ELISAs based on tachyzoite antigens showed a higher sensitivity than PCRs on tissue samples for detecting T. gondii infections in mice (Reperant et al., 2009), sheep (Glor et al., 2013) and pigs (Basso et al., 2017).

The dynamic of specific antibody reactions over time during experimental infection is immunoglobulin-specific (Lappin et al., 1989). IgM can be detected approximately 2 - 4 weeks post-inoculation, while specific IgG appears 1 week later (Lappin et al., 1989). Whilst IgM is elevated for approximately 16 weeks post-inoculation, IgG is thought to persist for life (Lappin et al., 1989), as documented by two further studies (Dubey, 1995; Afonso et al., 2006). 
The objective of this study was to analyze the antibody kinetics after experimental and natural infections over time, determine the seroprevalence in a client-owned Swiss cat population, as well as to identify potential risk factors for $T$. gondii infection in cats.

\section{Material and methods}

\subsection{Cat sera and plasma samples}

Sera from six cats experimentally inoculated with $T$. gondii in 2006 during so far unpublished studies, conserved in the serum sample collection of the Institute of Parasitology, University of Zurich, Switzerland, were included in the study. The cats were raised for laboratory use in the experimental animal facilities of the Institute of Parasitology, University of Zurich, and were negative for $T$. gondii by coproscopical examination ( $T$. gondii IFAT titer $<1: 25$; coproscopical analysis for $T$. gondii negative). Three 3 month old cats (SW, TB, TS: group 1) were orally inoculated with tissue cysts of a $T$. gondii type II isolate from France produced in mice (kindly provided by Prof. Candolfi, Institute of Parasitology and Tropical Pathology, Faculty of Medicine, Strasbourg, France), and three 6 month old cats (N, S, A: group 2) with 50,000 sporulated oocysts of a $T$. gondii type II European isolate. Serum samples were collected before and $3,6,9,12,18,24,31,45$ and 78 days post inoculation, and stored at $-20{ }^{\circ} \mathrm{C}$. During the experiment, feces were collected daily until euthanasia (3.5-5 months post inoculation) and analyzed by the sedimentation-flotation technique for $T$. gondii oocysts. After euthanasia, heart and diaphragm samples from all six cats were collected. Real-time PCR analysis from tissue was performed according to Cassaing et al. (2006) and showed a positive result in at least one of the two tissues in all cats which confirmed T. gondii infection. All animal experiments were authorized by the Cantonal Veterinary Office of Zurich, Switzerland (permission no. 140/2003).

Between 2011 and 2017 a total of 1,757 sera or plasma samples were collected from cats presented to the Small Animal Hospital of the Vetsuisse Faculty, University of Zurich (87\% of the total number of samples) or from private practices, laboratories or small animal hospitals located in Switzerland (13\% of the samples). The samples were submitted to the laboratories for different diagnostic purposes. Serial blood samples were available from 65 of the included cats, with a time span of at least 3 months between samples.

All samples were stored at $-20{ }^{\circ} \mathrm{C}$ until use. Data concerning the cats were collected from the patient records in the practice management system of the Small Animal Hospital of the Vetsuisse Faculty, or through the corresponding veterinarians. Age, date of sampling, gender, outside access, postal code and reason for admission were assessed for each cat if available. Cats with balcony access were defined as indoor, and cats with garden access as outdoor cats.

\subsection{Toxoplasma gondii ELISA}

ELISA was performed to detect specific IgG against tachyzoite surface antigens of $T$. gondii (Tg-ts-antigen). The $T$. gondii-tachyzoite surface-antigen (Tg-ts-antigen) was extracted using Triton X-100 (Sigma Aldrich, St. Louis, USA) from tachyzoites of T. gondii (Strain CH-Rab 3962 D8/94) harvested from human foreskin fibroblast (ATCC-LGC Standards Partnership; CRL-1634) in vitro cultures (Minbaeva et al., 2013). The 96 well ELISA plates (NUNC Maxisorp, Thermo Fisher Scientific, Waltham, USA) were coated with $100 \mu 1$ of Tg-ts-antigen $(5 \mu \mathrm{l} / \mathrm{ml})$ ELISA buffer I $\left(0.1 \mathrm{M}\right.$ carbonate-bicarbonate-buffer, $\left.\mathrm{pH} 9.6,4^{\circ} \mathrm{C}\right)$. The ELISA plates were washed with ELISA-wash solution I $(0.9 \% \mathrm{NaCl} / 0.3 \%$ Tween 20$)$ using an ELISA washing machine (Microplate Washer Tecan HydroSpeed, Tecan, Maennedorf, Switzerland) and blocked by adding ELISA buffer II (PBS / Tween 20 / bovine haemoglobin (Sigma Aldrich)). Each well was filled with $100 \mu 1$ of a 1:200 dilution of sera or plasma in buffer II. Several reference sera were included on every ELISA plate on different well positions: two 
replicates of one highly positive, three replicates of one weakly positive and two negative sera, as well as one serum-free conjugate control, and one substrate control. Diluted sera were incubated at $37{ }^{\circ} \mathrm{C}$ in a wet chamber for $1 \mathrm{~h}$. A conjugate anti-cat $\operatorname{IgG}$ ( $\gamma$-specific) produced in goat (KPL, Gaithersburg, USA), labeled with alkaline phosphatase, was diluted 1:1,000 with buffer II., Conjugate dilution (100 $\mu 1)$ was added and the plates were incubated. The substrate solution was composed of 4-nitrophenylphosphate (Sigma-Aldrich) and ELISA buffer III (0.05 $\mathrm{M}$ carbonate-bicarbonate-buffer, $\mathrm{pH} 9.8,4^{\circ} \mathrm{C}$ ) with a concentration of $1 \mathrm{mg} / \mathrm{ml}$. After washing the ELISA plate, $100 \mu 1$ of the substrate solution were added to each well and incubated at 37 ${ }^{\circ} \mathrm{C}$. The OD was analyzed at absorbance $\mathrm{A}_{405 \mathrm{~nm}}$ periodically, using the ELISA plate reader (Multiskan RC, Thermo LabSystems, Waltham, USA). When the high positive control reached approximately $\mathrm{OD}_{405} 1.5$, the $\mathrm{OD}_{405}$ values were noted. To reduce interassay variation, the $\mathrm{OD}_{405}$ values of each plate were adjusted according to the average of the three low seropositive controls included on every ELISA plate.

\subsection{Statistical analysis}

The frequency distribution of the $\mathrm{OD}_{405}$ values was assumed to be a bimodal mixture distribution. The probability distribution with the lower mode represents the $\mathrm{OD}_{405}$ values of the assumed negative cats and the probability distribution with the upper mode represents the assumed positive cats. The bimodal mixture distribution was analyzed as a mixture of two distributions taken from normal, lognormal, gamma, generalized beta and Weibull distributions, fitted by maximum likelihood to the same data using $\mathrm{R}$ [http://www.Rproject.org/]. The optimized mixture of distributions was compared via Akaike's Information Criterion (AIC) (Dohoo et al., 2007). The combination of two distributions which gave the lowest AIC value was considered to fit the data best (Dohoo et al., 2007). This gave the most likely probability distributions to which negative and positive cats belonged and thus enabled a probability of true infection status to be assigned to each cat. Mean probabilities of the true infection status across groups of cats represent an estimate of true prevalence.

Possible risk factors for high OD values and true prevalence were analyzed with generalized linear models (GLM) using R [http://www.R-project.org/]. The first model examined the association of $\mathrm{OD}_{405}$ value as the dependent variable, with gender, age, and outside access as possible independent variables. In the second model, the probability of positivity of each cat, assigned based on the results of the mixed model, was regressed against age, gender, and outside access.

Factors that had a $P$ value below 0.05 were defined as significantly associated with $\mathrm{OD}_{405}$ values or the probability of true positive status. Additionally, non-linear changes in $\mathrm{OD}_{405}$ values and the probability of true positive status with age and gender of the cats were evaluated with generalized additive models (GAM). Cats with and without outside access were analyzed independently.

The R code for the GLM and GAM analysis is provided as a supplementary file (http://dx.doi.org/10.17632/vzxdw9d5xp.1).

\subsection{Data accessibility}

All supplementary files are available at Mendeley Data:

http://dx.doi.org/10.17632/vzxdw9d5xp.1. 


\section{Results}

The six experimentally inoculated cats seroconverted between 2 - 3 weeks post inoculation, independently of whether they were inoculated with sporulated oocysts or with tissue cysts (Fig. 1). Furthermore, no differences in the serological responses were observed in these two groups of cats. While cats experimentally inoculated with tissue cysts (Fig. 1A) shed oocysts within 5 - 8 days, beginning at 4 - 7 days after inoculation, cats inoculated with oocysts (Fig. 1B) did not shed oocysts during the whole observation period of several months.

The IgG level variation over time in the 65 cats with serial blood sampling (0.3-5.2 years apart) is displayed in Fig. 2 and presented into three groups including cats with a greater than $80 \%$ probability of being seropositive with a IgG level variation less than $25 \%$ in group a $(n=13)$ (Fig. 2A), cats with a IgG level variation over $25 \%$ of the initial $\mathrm{OD}_{405}$ value with a greater than $80 \%$ probability of being seropositive in the follow-up examination in group b $(n=11)$ (Fig. 2B) and cats with a lower than $80 \%$ probability of being seropositive cats remaining most likely seronegative in group c $(n=41)$ (Fig. 2C). In two probably seropositive cats from group b the IgG levels decreased over $25 \%$ of the $\mathrm{OD}_{405}$ value, however the probability of being positive was still above 99\%; in five further seropositive cats, the absorbance values increased above $25 \%$ over time and three initially most likely seronegative cats seroconverted between $1-3,6$ - 8 and 6 - 7 years of age, and a further cat seroconverted at approximately 15 years of age (Fig. 2B). All four initially seronegative cats had outside access. No cat which initially tested positive, tested negative in follow-up examinations.

The median age (range: 0.08 - 22.01 years) of the 1,757 cats was 9 years; for $1 \%$ of the cats the age was unknown. Fifty-eight percent $(1,024 / 1,757$ cats $)$ had outside access, $33 \%(582 / 1,757$ cats) were indoor-only cats, and the status "outdoor-access" was unknown for $9 \%(151 / 1,757)$ of the cats. Female and male cats accounted for $42 \%$ (732/1,757 cats) and 56\% (983/1,757 cats) of the animals, respectively, while the gender was unknown for $2 \%(42 / 1,757)$ of the cats. Ninety-two percent (907/983 cats) of the male and $84 \%$ (613/732 cats) of the female cats were neutered. In total, $87 \%(1,520 / 1,757)$ of the cats were neutered.

A total of 1,757 cat sera or plasma samples were examined for the presence of IgG against $\mathrm{Tg}$ ts-antigens. Based on the AIC, a mixture of lognormal and Weibull distributions was the optimum combination of two distributions to fit the data. This mixture of distributions had an AIC of -1,273.8, compared with, for example two normal distributions (AIC $=-988.9$ ), two lognormal distributions (AIC $=-1,099.02$ ) or two Weibull distributions (AIC $=-1,162.95)$ (Fig. 3 ). For each $\mathrm{OD}_{405}$ value the probability of the cat being a true positive could then be calculated. This is illustrated in Fig. 4.

Of the client-owned cats, $42.4 \%$ (95\% CI: 40.1-44.6) had a positive true infection status. This was higher (56.3\% (95\% CI: 53.2-59.6)) in cats with outside access than in those cats kept exclusively indoors (22.1\% (95\% CI: 18.9-25.4)). Estimated prevalences for indoor and outdoor cats plus male and female cats are given in Table 1.

Risk factors that were independently associated with significantly higher $\mathrm{OD}_{405}$ values in the multiple GLM analyses of the 1,757 client-owned cats were "age" (parameter $=0.05, P<0.0001$ ), "gender" (male: parameter $=0.26, P=0.046)$ ), and "outside access" (parameter $=1.1, P<0.0001$ ). When interaction effects were analyzed, male cats with outside access had a highly significant increase in OD values compared with female cats with outside access $(P<0.0001)$, whilst for indoor cats the significance was marginal $(P=0.046)$. For this GLM a Weibull model was found to give the best description of the data. Interactions between risk factors were also examined. In the second model, the probability of being positive increased non-linearly with age $(P<0.0001)$, was higher with outside access $(P<0.0001)$ and in male cats with outside access $(P=0.0006)$. In this case only the interaction term with gender was significant, indicating that 
male cats had a higher probability of being positive only if they had outside access. For cats with no outside access there was no statistical association between probability of positivity and gender.

The factor "neutered" was analyzed in each model but was found to be insignificant and was removed from the analysis. For the continuous variable age, the non-linear variation in probability of a true positive with age is illustrated in Fig. 5. The non-linear GAM gave the best fit, AIC for the GLM was -20,387.8 compared with the AIC for the GAM which was -20,389.9 (Fig. 5). With increasing age of the cats, the number of data points decreased and therefore the confidence interval increased.

Data of the 1,757 client-owned cats and $\mathrm{R}$ code are given in additional files at Mendeley Data (http://dx.doi.org/10.17632/vzxdw9d5xp.1).

\section{Discussion}

Interestingly, the antibody kinetics against Tg-ts-antigen of cats inoculated with Toxoplasma cysts or sporulated oocysts, showed no difference despite earlier described different prepatencies (Wallace, 1973; Dubey, 2002). This suggests that the cats are exposed to tachyzoites shortly after the intestinal invasion of bradyzoites or sporozoites. It was hypothesized that bradyzoites are probably precursors of enteroepithelial replication and therefore they enable a quicker intestinal development (Dubey and Lappin, 2006). In our experiment, none of the three cats inoculated with oocysts developed patency, which is in concordance with findings of other studies (Dubey, 1996). The sample size (three cats) in our study is small and therefore it does not allow a statistical analysis. However, this finding emphasizes the fact that seroconversion is not always attended by patency and therefore it does not allow the conclusion that all seropositive cats had at least one patent episode.

To the authors' knowledge, the present study is the first analyzing the immune response over time in client-owned cats with presumably discontinuous exposure to T. gondii. Analysis of the serial blood samples of the 65 cats suggested no remarkable change in ELISA values over time. A long-term humoral response is essential to enable analysis of prevalence via serology. This finding would contradict the hypothesis from Opsteegh et al. (2012), stating that the steady seroprevalence of cats older than 12 years is due to an equal number of cats seroconverting and reverting to seronegative, and is in consensus with a study from Dubey et al. (1995), observing that the specific IgG levels of nine cats experimentally fed $T$. gondii tissue cysts did not decline beneath the cut-off over 6 years. Additionally, a further study on stray cats captured several times within a 10 year observation period showed that the IgG levels did not significantly change over time (Afonso et al., 2006).

The seroprevalence of antibodies against $T$. gondii in Swiss cats of $42 \%$ is within the range of other European countries: 61\% in Estonia (Must et al., 2015), 36\% and 21\% in Portugal ( Lopes et al., 2008; Esteves et al., 2014), 18\% in the Netherlands (Opsteegh et al., 2012), 52\% in Latvia (Deksne et al., 2013), 47\% in Romania (Györke et al., 2011), 25\% in Belgium (De Craeye et al., 2008), 45 and 32\% in Spain (Gauss et al., 2003; Miró et al., 2004), 41\% in Norway (Sævik et al., 2015) and $41 \%$ in Finland (Must et al., 2017). However, considering the different sample sizes, animal sampling (e.g. average age, outside access, exposure to risk factors), test characteristics, and environmental factors, a direct comparison of the results in the different studies is difficult.

Swiss screening programs for congenital toxoplasmosis showed a decline in seroprevalence in pregnant women from 1982 to 2015 (Rudin et al., 2018). Risk awareness, changes in dietary behavior and meat production are thought to be possible reasons for this decline (Rudin et al., 
2018). This indicates an increased susceptibility for initial infections during pregnancy. The frequency of infection depends not only on the susceptibility, but also on the risk of exposure (Larsen and Lebech, 1994). An important source of infection in humans according to the European Food Safety Authority Panel on Biological Hazards [https://www.efsa.europa.eu/de/panels/biohaz] is thought to be foodborne and to account for $61 \%$ of the T. gondii infections with a broad $95 \%$ uncertainty interval of 35 to $82 \%$ in Europe based on expert knowledge elicitation (Hald et al., 2016; EFSA et al., 2018). Oocyst shedding cats are assumed to be highly epidemiologically significant for the distribution of $T$. gondii based on studies showing a high seroprevalence among vegetarians (Hall et al., 1999), a low prevalence in pigs (van Knapen et al., 1995) and in meat from different livestock species (Dubey et al., 2005; Berger-Schoch et al., 2011), as well as significantly lower seroprevalences on cat-free islands (Wallace, 1969; Dubey et al., 1997). Therefore, surveillance of the seroprevalence in cats is thought to be an important parameter to assess the risk of exposure. However, as shown in the present study and described previously, seroconversion may occur without oocyst shedding; hence not all seropositive cats have shed oocysts (Dubey et al., 1995). Data from Switzerland showed that the frequency of domestic cats shedding $T$. gondii oocysts was between $0.4 \%$ (Frey et al., 2012) and $0.6 \%$ (Zottler et al., 2019).

In this study, the observed seroprevalence of $22.1 \%$ in cats with no outside access was high. Possible reasons are that these cats had outside access in the past, or that they were infected indoors through their diet, including raw meat, as well as other types of food (e.g. vegetables) contaminated with oocysts, or oocysts accidentally carried inside by the owners. Feeding a Bones and Raw Food (BARF) diet has become a popular trend as improved health, immune status, coat quality and longevity have been advocated by proponents (Billinghurst, 2001). Unfortunately, the diet of the studied cat population could not be assessed.

Consistent with the results of the present study, outside access (Miró et al., 2004; Lopes et al., 2008; Opsteegh et al., 2012) and age (Miró et al., 2004; Afonso et al., 2006; Opsteegh et al., 2012) were significantly associated with $T$. gondii seropositivity in most other studies worldwide. Male cats had a marginally significantly greater OD value compared with female cats. The interactions demonstrated that this was mainly due to the outdoor male cats. This was more pronounced when analyzing the probability of infection. Male cats, whether neutered or intact, with outside access had a higher probability of infection, whereas there was no significant difference between male and female cats which were kept entirely indoors. This may possibly be because males are thought to have wider hunting territories than females, and thus a higher risk of exposure, or through more frequent re-exposure as previously described in pigs (Warnar, 1985; Smith et al., 1992; Basso et al., 2017). This association was previously reported in three other studies (Miró et al., 2004; Vollaire et al., 2005; Sævik et al., 2015).

Bioassay in cats or mice was suggested as a possible "gold standard" method to confirm $T$. gondii infection; however, this techniques cannot be applied in all situations (e.g. on living animals). These are expensive, time consuming, and arguable regarding ethical and animal welfare aspects (Glor et al., 2013). Hence, as there is no feasible "gold standard" test able to clearly distinguish between infected and non-infected cats, the prevalences were calculated from the data on probabilities of true infection status assigned to each cat based on the assumption that there is a bimodal probability density, with the two models representing the most common $\mathrm{OD}_{405}$ values for negative and positive cats. This model reflects the reality, that there is no absolute certainty whether a cat is positive or not.

There are several possible reasons for misclassification of cats as seropositive or -negative by ELISA. One possible explanation for false positive results in young cats (younger than 8 - 12 weeks) is the transmission of maternally-derived antibodies (Omata et al., 1994). However, only a few cats in our study ( 15 cats, $0.85 \%$ of the cat population studied) were younger than 12 weeks. Another origin of false positive results is the occurrence of possible cross-reactions 
with epitopes of closely related species (Gondim et al., 2017). Young cats are likely to have less cross-reactions than older cats, due to the lack of exposure to potential cross-reacting antigens. The advantage of using the conjugate anti feline $\operatorname{IgG}$ ( $\gamma$-specific), as used in this study, is that it is known not to react either with cat $\operatorname{IgA}$ or with $\operatorname{IgM}$, avoiding false positive results due to the low specificity of IgM tests (Konishi, 1991; Liesenfeld et al., 1997; Montoya, 2002). On the other hand IgM is thought to rise earlier than IgG after infection (Lappin et al., 1989; Omata et al., 1990). Acute infections could be misclassified as negative; nevertheless the IgG level rise after exposure is rapid as shown in Fig. 1. All cats were clearly seropositive 2 - 3 weeks after inoculation, indicating that only a small number of cats could be falsely classified as negative.

There are several limitations to this study. Regarding the cat population, a selection bias cannot be excluded, as there is no data concerning the age distribution of the current Swiss cat population. Young and old cats could be slightly overrepresented due to the fact that the blood samples were collected mostly for clinical reasons. Furthermore, as blood withdrawal is more likely performed in well taken care of and perhaps immunocompromised cats, a distortion of the seroprevalence is possible. Concerning the ELISA results, unfortunately, no "gold standard" reference method with $100 \%$ sensitivity and specificity is available and other methods such as PCR or bioassay cannot be applied in our study to verify the serological results. Another limitation of the current study was that potential confounders such as being fed raw meat or individual behavior of the cat including hunting habits, could not be assessed.

In conclusion, our data suggest exposure to tachyzoites at the same time point after infection, independent of a cat's first exposure to tissue cysts or to oocysts. Furthermore, our results strengthens the hypothesis of a long-term or even lifelong humoral immune response after $T$. gondii infection in cats and suggest that the T. gondii seroprevalence in cats in Switzerland is high $(42 \%)$ and that the odds of being seropositive increase with age, are higher with outside access and higher in male cats with outside access. The results of the study provide a basis for future surveillance of $T$. gondii prevalence in Switzerland. 


\section{Conflict of interest:}

The authors have no conflict of interest to declare. This research did not receive any specific grant from funding agencies in the public, commercial, or not-for-profit sectors.

This work represents part of the doctoral dissertation of Nora Schreiber.

\section{Appendix Supplementary Data}

Supplementary data are available online at http://dx.doi.org/10.17632/vzxdw9d5xp.1. 


\section{References}

Afonso, E., Thulliez, P., Gilot-fromont, E., 2006. Transmission of Toxoplasma gondii in an urban population of domestic cats (Felis catus). Int. J. Parasitol. 36, 1373-1382.

Basso, W., Grimm, F., Ruetten, M., Djokic, V., Blaga, R., Sidler, X., Deplazes, P., 2017. Experimental Toxoplasma gondii infections in pigs: humoral immune response, estimation of specific IgG avidity and the challenges of reproducing vertical transmission in sows. Vet. Parasitol. 236, 76-85.

Berger-Schoch, A.E., Herrmann, D.C., Schares, G., Müller, N., Bernet, D., Gottstein, B., Frey, C.F., 2011. Prevalence and genotypes of Toxoplasma gondii in feline faeces (oocysts) and meat from sheep, cattle and pigs in Switzerland. Vet. Parasitol. 177, 290-297.

Billinghurst, I., 2001. The Barf diet: raw feeding for dogs and cats using evolutionary principles. Self-published, Barthurst NSW Australia.

Cassaing S., Bessie, M.H., Berry, A., Berrebi, A., Fabre, R., Magnaval, J.F., 2006. Comparison between two amplification sets for molecular diagnosis of toxoplasmosis by real-time PCR, J. Clin. Microbiol. 44, 720-724.

De Craeye, S., Francart, A., Chabauty, J., De Vriendt, V., Van Gucht, S., Leroux, I., Jongert, E., 2008. Prevalence of Toxoplasma gondii infection in Belgian house cats. Vet. Parasitol. 157, 128-132.

Deksne, G., Petrusēviča, A., Kirjušina, M., 2013. Seroprevalence and factors associated with Toxoplasma gondii infection in domestic cats from urban areas in Latvia. J. Parasitol. $99,48-50$.

Dohoo, I., Martin, W., Stryhn, H. Model-building strategies, statistical considerations - nonnested models. In: Dohoo, I., Martin, W., Stryhn, H. (Ed.), 2007. Veterinary epidemiologic research, 2nd ed., AVC Inc., Charlottetown, pp. 325-327.

Dubey, J. P., Miller, N.L., Frenkel, J.K., 1970. The Toxoplasma gondii oocyst from cat feces. J. Exp. Med. 132, 636-362.

Dubey, J.P., Frenkel, J.K., 1976. Feline toxoplasmosis from acutely infected mice and the development of Toxplasma cysts. J. Protozool. 23, 537-546.

Dubey, J.P., Beattie, C.P., 1988. Toxoplasmosis of animals and man. CRC Press, Boca Raton.

Dubey, J.P., Carpenter, J.L., 1993. Histologically confirmed clinical toxoplasmosis in cats: 100 cases (1952-1990). J. Am. Vet. Med. Assoc. 203, 1556-1566.

Dubey, J.P., 1995. Duration of immunity to shedding of Toxoplasma gondii oocysts by cats. J. Parasitol. 81, 410-415.

Dubey, J.P., Lappin, M.R., Thulliez, P., 1995. Long-Term antibody responses of cats fed Toxoplasma gondii tissue cysts. J. Parasitol. 81, 887-893.

Dubey, J.P., Mattix, M.E., Lipscomb, T.P., 1996. Lesions of neonatally induced toxoplasmosis in cats. Vet. Pathol. 33, 290-295.

Dubey, J.P., 1996. Infectivity and pathogenicity of Toxoplasma gondii oocysts for cats. J. 
Parasitol. 82, 957-961.

Dubey, J.P., Rollor, E.A., Smith, K., Kwok, O.C., Thulliez, P., 1997. Low seroprevalence of Toxoplasma gondii in feral pigs from a remote island lacking cats. J. Parasitol. 83, 839841.

Dubey, J.P., 2002. Tachyzoite-induced life cycle of Toxoplasma gondii in cats. J. Parasitol. 88, $713-717$.

Dubey, J.P., Hill, D.E., Jones, J.L., Hightower, A.W., Kirkland, E., Roberts, J.M., Marcet, P.L., Lehmann, T., Vianna, M.C.B., Miska, K., Sreekumar, C., Kwok, O.C.H., Shen, S.K., Gamble, H.R., Roaberts, J.M., 2005. Prevalence of viable Toxoplasma gondii in beef, chicken, and pork from retail meat stores in the United States: risk assessment to consumers. J. Parasitol. 91, 1082-1093.

Dubey, J.P., Lappin, M.R., Toxoplasmosis and Neosporosis. In: Greene, C.E. (Ed.), 2006. Infectious diseases of the dog and cat. 3rd ed. Saunders WB, Philadelphia. pp. 754-768.

EFSA Panel on Biological Hazards (BIOHAZ), Koutsoumanis, K., Allende, A., AlvarezOrdóñez, A., Bolton, D., Bover-Cid, S., Chemaly, M., Davies, R., De Cesare, A., Herman, L., Hilbert, F., Lindqvist, R., Nauta, M., Peixe, L., Ru, G., Simmons, M., Skandamis, P., Suffredini, E., Cacciò, S., Chalmers, R., Deplazes, P., Devleesschauwer, B., Innes, E., Romig, T., van der Giessen, J., Hempen, M., van der Stede, Y., Robertson, L., 2018. Public health risks associated with food-borne parasites. EFSA J. 16, e05495.

Esteves, F., Aguiar, D., Rosado, J., Costa, M.L., de Sousa, B., Antunes, F., Matos, O., 2014. Toxoplasma gondii prevalence in cats from Lisbon and in pigs from centre and south of Portugal. Vet. Parasitol. 200, 8-12.

Frenkel, J.K., Dubey, J.P., Miller, N.L., 1970. Toxoplasma gondii in cats: faecal stages identified as coccidian oocysts. Science 167, 893-896.

Frenkel, J.K., Ruiz, A., Chinchilla, M., 1975. Soil survival of Toxoplasma oocysts in Kansas and Costa Rica. Am. J. Trop. Med. Hyg. 24, 439-443.

Frey, C., Berger-Schoch, A., Herrmann, D., Schares, G., Müller, N., Bernet, D., Doherr, M.G., Gottstin, B., 2012. Incidence and genotypes of Toxoplasma gondii genotypes in the muscle of sheep, cattle and pigs as well as in cat feces in Switzerland [Vorkommen und Genotypen von Toxoplasma gondii in der Muskulatur von Schaf, Rind und Schwein sowie im Katzenkot in der Schweiz] (German). Schweiz. Arch. Tierheilkd. 154, 251255.

Gauss, C.B.L., Almería, S., Ortuño, A., Garcia, F., Dubey, J.P., 2003. Seroprevalence of Toxoplasma gondii antibodies in domestic cats from Barcelona, Spain. J. Parasitol. 89, 1067-1068.

Glor, S.B., Edelhofer, R., Grimm, F., Deplazes, P., Basso, W., 2013. Evaluation of a commercial ELISA kit for detection of antibodies against Toxoplasma gondii in serum, plasma and meat juice from experimentally and naturally infected sheep. Parasite Vector $6,1-11$.

Gondim, L.F.P., Mineo, J.R., Schares, G., 2017. Importance of serological cross-reactivity among Toxoplasma gondii, Hammondia spp., Neospora spp., Sarcocystis spp. and 
Besnoitia besnoiti. Parasitology 144, 851-868.

Györke, A., Opsteegh, M., Mircean, V., Iovu, A., Cozma, V., 2011. Toxoplasma gondii in Romanian household cats: Evaluation of serological tests, epidemiology and risk factors. Prev. Vet. Med. 102, 321-328.

Hald, T., Aspinall, W., Devleesschauwer, B., Cooke, R., Corrigan, T., Havelaar, A.H., Gibb, H.J., Torgerson, P.R., Kirk, M.D., Angulo, F.J., Lake, R.J., Speybroeck, N., Hoffmann, S., 2016. World Health Organization estimates of the relative contributions of food to the burden of disease due to selected foodborne hazards: A structured expert elicitation. PLoS One 11, 1-35.

Hall, S.M., Pandit, A., Golwilkar, A., Williams, T.S., 1999. How do Jains get Toxoplasma infection? Lancet 354, 486-487.

Konishi, E., 1991. Naturally occurring immunoglobulin M antibodies to Toxoplasma gondii in Japanese populations. Parasitology 102, 157-162.

Lappin, M.R., 2010. Update on the diagnosis and management of Toxoplasma gondii infection in cats. Top. Companion Anim. Med. 25, 136-141.

Lappin, M.R., Greene, C.E., Prestwood, A.K., Dawe, D.L., Tarleton, R.L., 1989. Diagnosis of recent Toxoplasma gondii infection in cats by use of an enzyme-linked immunosorbent assay for immunoglobulin M. Am. J. Vet. Res. 50, 1580-1585.

Larsen, S.O., Lebech, M., 1994. Models for prediction of the frequency of toxoplasmosis in pregnancy in situations of changing infection rates. Int. J. Epidemiol. 23, 1309-1314.

Liesenfeld, O., Press, C., Montoya, J.G., Gill, R., Isaac-Renton, J.L., Hedman, K., Remington, J.S., 1997. False-positive results in immunoglobulin M (IgM) Toxoplasma antibody tests and importance of confirmatory testing: The Platelia Toxo IgM test. J. Clin. Microbiol. $35,174-178$.

Lopes, A.P., Cardoso, L., Rodrigues, M., 2008. Serological survey of Toxoplasma gondii infection in domestic cats from northeastern Portugal. Vet. Parasitol. 155, 184-189.

Minbaeva, G., Schweiger, A., Bodosheva, A., Kuttubaev, O., Hehl, A.B., Tanner, I., Ziadinov, I., Torgerson, P.R., Deplazes, P., 2013. Toxoplasma gondii infection in Kyrgyzstan: seroprevalence, risk factor analysis, and estimate of congenital and AIDS-related toxoplasmosis. PLoS Negl. Trop. Dis. 7, 1-7.

Miró, G., Montoya, A., Jiménez, S., Frisuelos, C., Mateo, M., Fuentes, I., 2004. Prevalence of antibodies to Toxoplasma gondii and intestinal parasites in stray, farm and household cats in Spain. Vet. Parasitol. 126, 249-255.

Montoya, J.G., 2002. Laboratory diagnosis of Toxoplasma gondii infection and toxoplasmosis. J. Infect. Dis. 185 Suppl., 73-82.

Must, K., Hytönen, M.K., Orro, T., Lohi, H., Jokelainen, P., 2017. Toxoplasma gondii seroprevalence varies by cat breed. PLoS One 12,1-10.

Must, K., Lassen, B., Jokelainen, P., 2015. Seroprevalence of and risk factors for Toxoplasma gondii infection in cats in Estonia. Vector-Borne Zoonotic Dis. 15, 597-601. 
Omata, Y., Oikawa, H., Kanda, M., Mikazuki, K., Dilorenzo, C., Claveria, F.G., Takahashi, M., Igarashi, I., Saito, A., Suzuki, N., 1994. Transfer of antibodies to kittens from mother cats chronically infected with Toxoplasma gondii. Vet. Parasitol. 52, 211-218.

Omata, Y., Oikawa, H., Kanda, M., Mikazuki, K., Nakabayashi, T., Suzuki, N., 1990. Experimental feline toxoplasmosis: humoral immune responses of cats inoculated orally with Toxoplasma gondii cysts and oocysts. Jpn. J. Vet. Sci. 52, 865-867.

Opsteegh, M., Haveman, R., Swart, A.N., Mensink-Beerepoot, M.E., Hofhuis, A., Langelaar, M.F.M., van der Giessen, J.W.B., 2012. Seroprevalence and risk factors for Toxoplasma gondii infection in domestic cats in the Netherlands. Prev. Vet. Med. 104, 317-326.

Pardini, L., Maksimov, P., Herrmann, D.C., Bacigalupe, D., Rambeaud, M., Machuca, M., Moré, G., Basso, W., Schares, G., Venturini, M.C., 2012. Evaluation of an in-house TgSAG1 (P30) IgG ELISA for diagnosis of naturally acquired Toxoplasma gondii infection in pigs. Vet. Parasitol. 189, 204-210.

Powell, C.C., Brewer, M., Lappin, M.R., 2001. Detection of Toxoplasma gondii in the milk of experimentally infected lactating cats. Vet. Parasitol. 102, 29-33.

Reperant, L.A., Hegglin, D., Tanner, I., Fischer, C., Deplazes, P., 2009. Rodents as shared indicators for zoonotic parasites of carnivores in urban environments. Parasitology 136, 329-337.

Rudin, C., Hirsch, H.H., Spaelti, R., Schaedelin, S., Klimkait, T., 2018. Decline of seroprevalence and incidence of congenital toxoplasmosis despite changing prevention policy-three decades of cord-blood screening in north-western Switzerland. Pediatr. Infect. Dis. J. 37, 1087-1092.

Sævik, B.K., Krontveit, R.I., Eggen, K.P., Malmberg, N., Thoresen, S.I., Prestrud, K.W., 2015. Toxoplasma gondii seroprevalence in pet cats in Norway and risk factors for seropositivity. J. Feline Med. Surg. 17, 1049-1056.

Skariah, S., McIntyre, K., Mordue, D. G. 2010. Toxoplasma gondii: determinants of tachyzoite to bradyzoite conversion. Parasitol. Res. 107, 253-260.

Smith, K.E., Zimmerman, J.J., Patton, S., Beran, G.W., Hill, H.T., 1992. The epidemiology of toxoplasmosis in Iowa swine farms with an emphasis on the roles of free-living mammals. Vet. Parasitol. 42, 199-211.

Tenter, A., Heckeroth, A., Weiss, L., 2000. Toxoplasma gondii: from animals to humans. Int. J. Parasitol. 30, 1217-1258.

van Knapen, F., Kremers, A.F., Franchimont, J.H., Narucka, U., 1995. Prevalence of antibodies to Toxoplasma gondii in cattle and swine in the Netherlands: towards an integrated control of livestock production. Vet. Q. 17, 87-91.

Vollaire, M.R., Radecki, S.V., Lappin, M.R., 2005. Seroprevalence of Toxoplasma gondii antibodies in clinically ill cats in the United States. Am. J. Vet. Res. 66, 874-877.

Wallace, G.D., 1969. Serologic and epidemiologic observations on toxoplasmosis on three Pacific atolls. Am. J. Epidemiol. 90, 103-111.

Wallace, G. D., 1973. The role of the cat in the natural history of Toxoplasma gondii. Am. J. 
Trop. Med. Hyg. 22, 313-322.

Warnar, R.E., 1985. Demography and movements of free-ranging domestic cats in rural Illinois . J. Wildl. Manage. 49, 340-346.

Weiss, L.M., Dubey, J.P., 2009. Toxoplasmosis: a history of clinical observations. Int. J. Parasitol. 39, 895-901.

Zottler, E.M., Bieri, M., Basso, W., Schnyder, M., 2019. Intestinal parasites and lungworms in stray, shelter and privately owned cats of Switzerland. Parasitol. Int. 69, 75-81. 


\section{Figure Captions}

Fig. 1. Antibody absorbance over time of the six cats orally inoculated with Toxoplasma gondii. (A) Three cats (SW, TB, TS) were inoculated with $T$. gondii tissue cysts, and (B) three cats (N, $\mathrm{S}, \mathrm{A}$ ) were inoculated with 50,000 oocysts (X-axis: time in days, day $0=$ day of inoculation; Y-axis: $\mathrm{OD}_{405}$ values of the T. gondii ELISA).

Fig. 2. Antibody absorbance over time of the 65 cats with repetitive blood samples. (A) Cats with a greater than $80 \%$ probability of being seropositive with a IgG level variation less than $25 \%(n=13)$. (B) Cats with a greater than $80 \%$ probability of being seropositive in the followup examination and with a IgG level variation over $25 \%$ of the initial $\mathrm{OD}_{405}$ value $(n=11)$. (C) Cats with a lower than $80 \%$ probability of being seropositive, most likely remaining seronegative $(n=41)\left(\mathrm{X}\right.$-axis: time in years, year $0=$ year of first blood collection; $Y$-axis: $\mathrm{OD}_{405}$ values of the Toxoplasma gondii ELISA).

Fig. 3. Bimodal frequency distribution of $\mathrm{OD}_{405}$ values of client-owned cats $(n=1,757)$ analyzed for antibodies (IgG) against Toxoplasma gondii tachyzoite surface antigens using ELISA (Xaxis: $\mathrm{OD}_{405}$ values; Y-axis: frequency; bars: individual cats; curved lines: mixture of lognormal and Weibull distributions).

Fig. 4. Variation of probability of the cats being true positive for Toxoplasma gondii infection with the $\mathrm{OD}_{405}$ value, calculated based on the results of the mixed model (X-axis: OD value; Yaxis: probability of true positive).

Fig. 5. Non-linear changes in the probability of a true positive status with age of the cats with outside access, evaluated with generalized additive models (GAM). Dotted lines indicate the 95\% confidence intervals (CI), $x$ scale indicates density of the data (X-axis: ages of the cats in years; Y-axis: proportion of cats positive for Toxoplasma gondii infection). 


\section{Table Legends}

Table 1: Estimated true prevalence of toxoplasmosis and confidence intervals $(\mathrm{CI})$ in various groups of the 1,757 client-owned cats included in the study.

\begin{tabular}{ll}
\hline Type of cat & Prevalence $($ CI $)$ \\
\hline Male & $0.457(0.426-0.487)$ \\
Female & $0.379(0.344-0.413)$ \\
Outside & $0.563(0.532-0.596)$ \\
Inside & $0.221(0.189-0.254)$ \\
\hline All cats & $0.424(0.401-0.446)$ \\
\hline
\end{tabular}


Figures 
Figure 1

A)

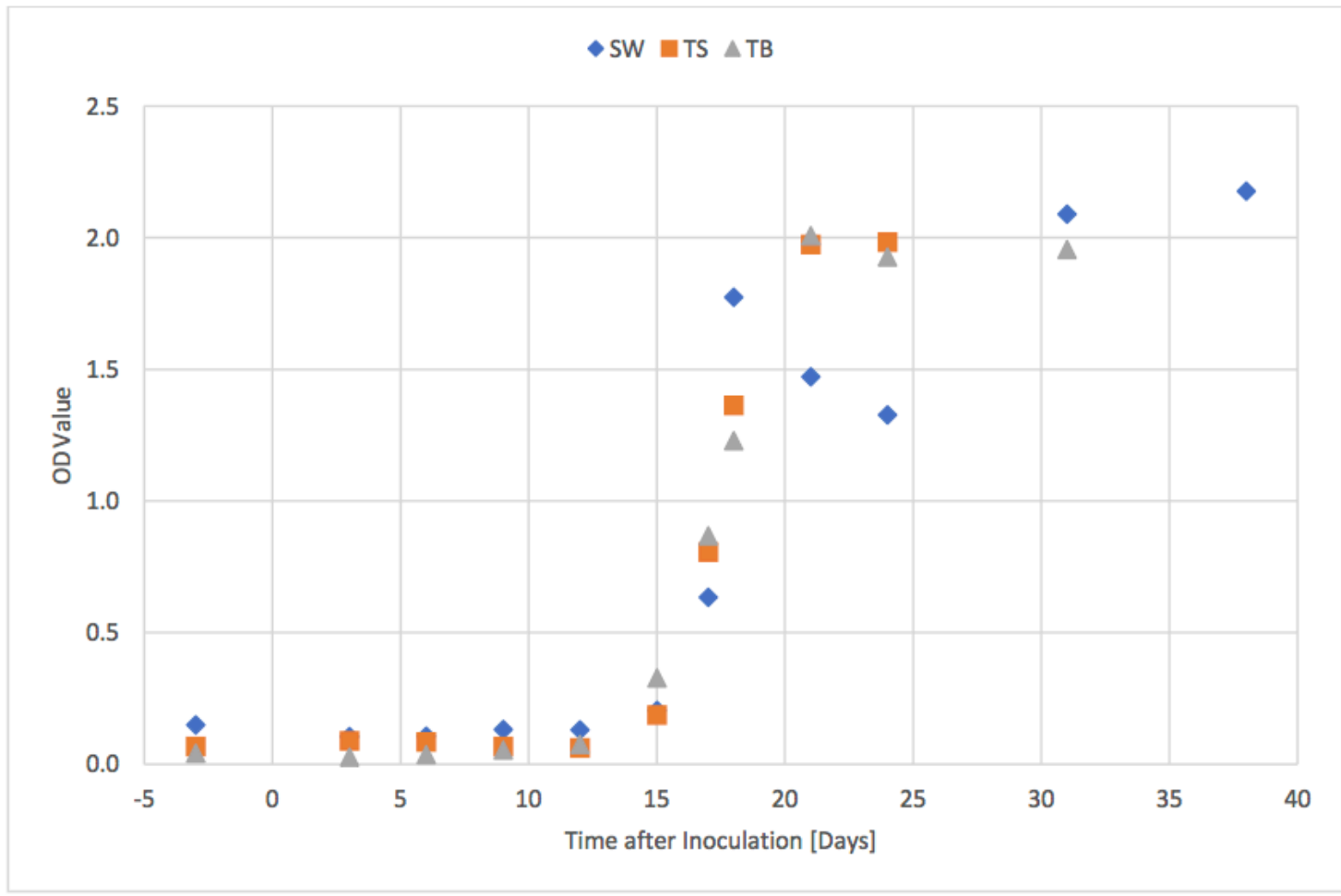

B)

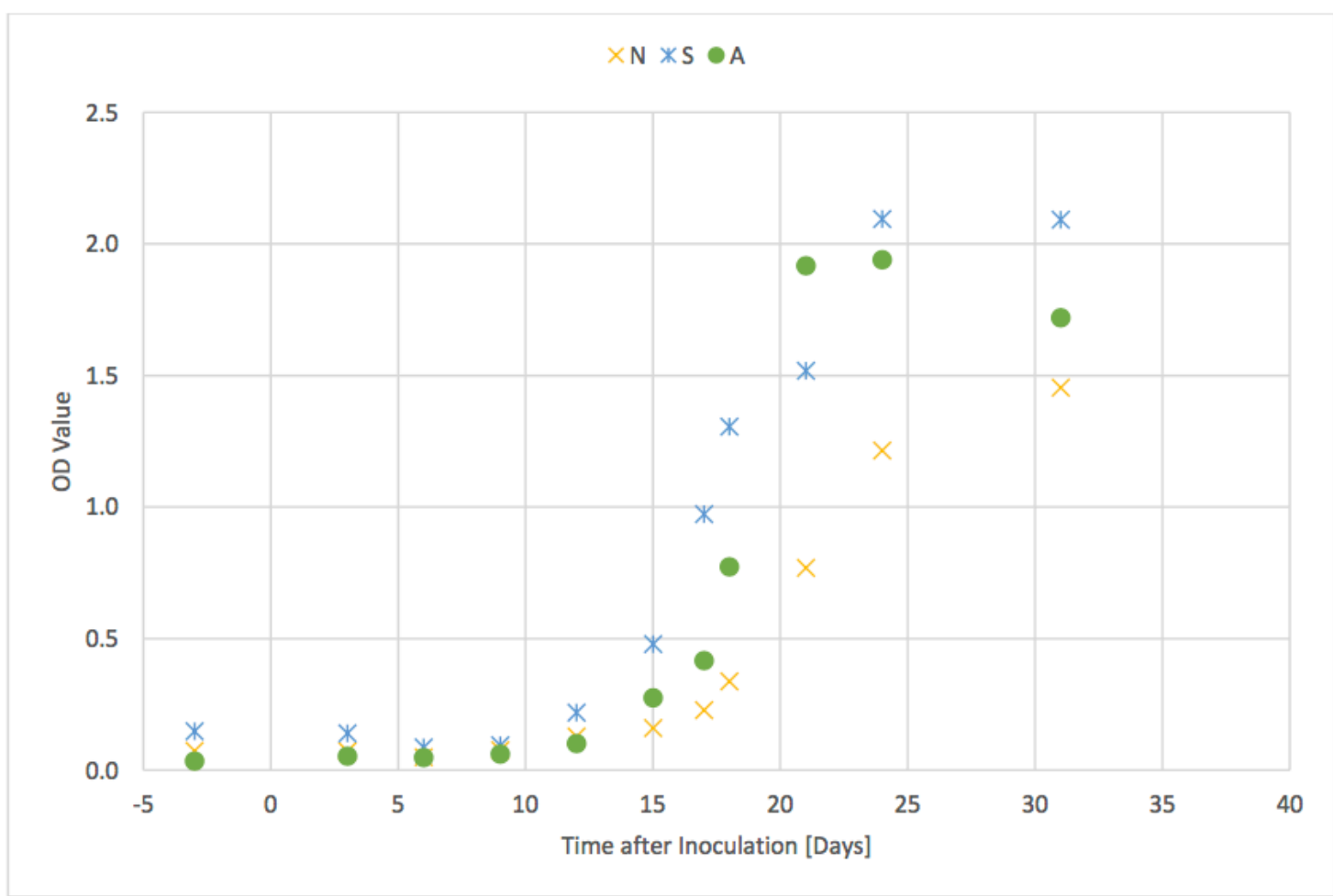


Figure 2

A)

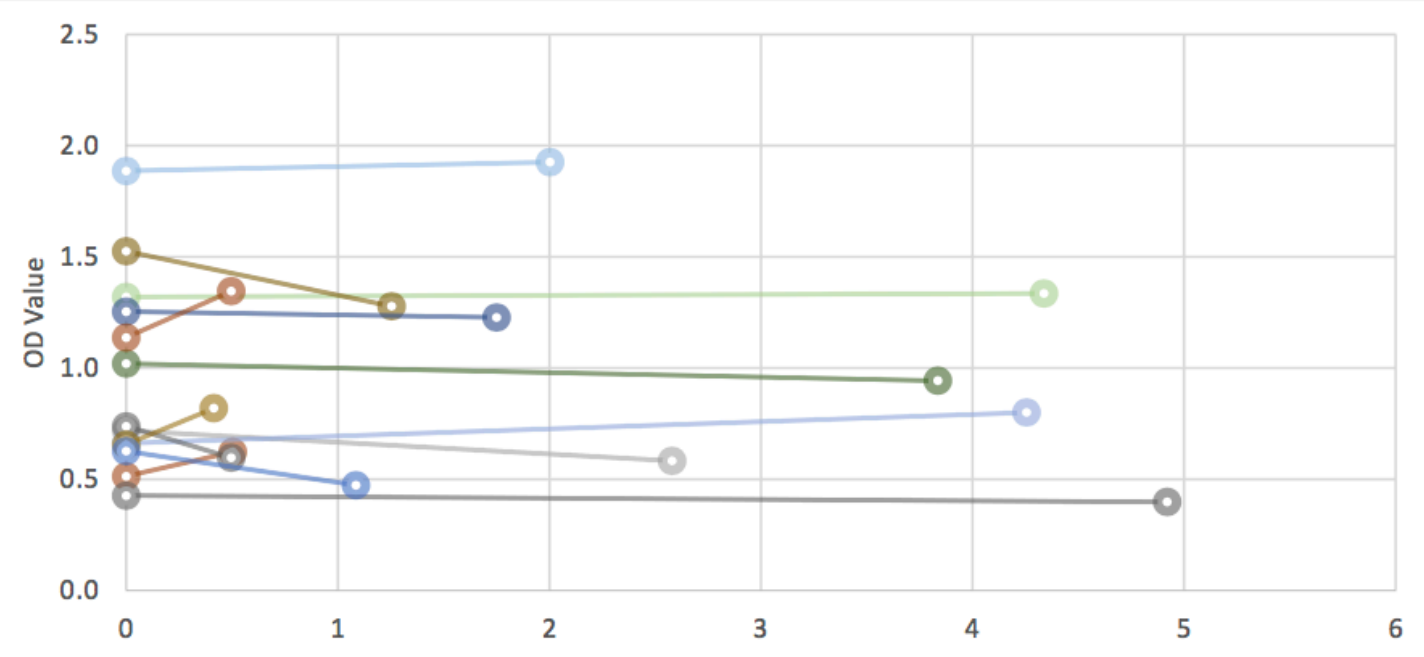

B)

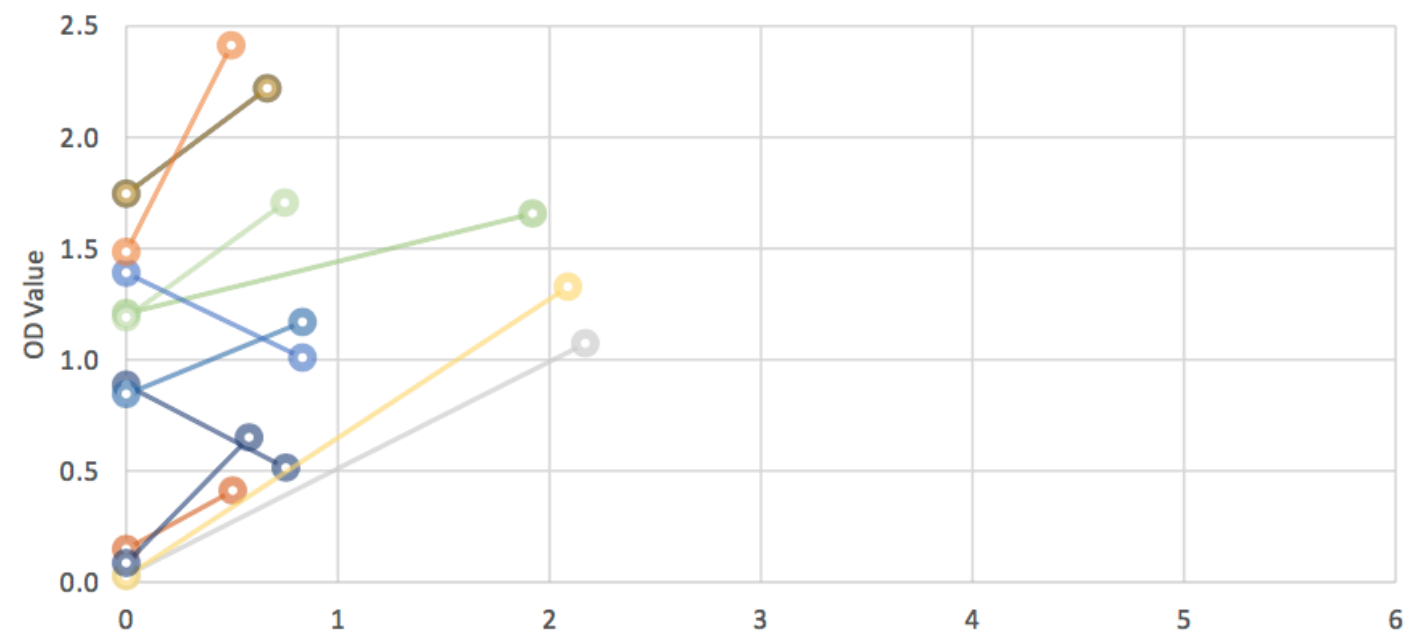

C)

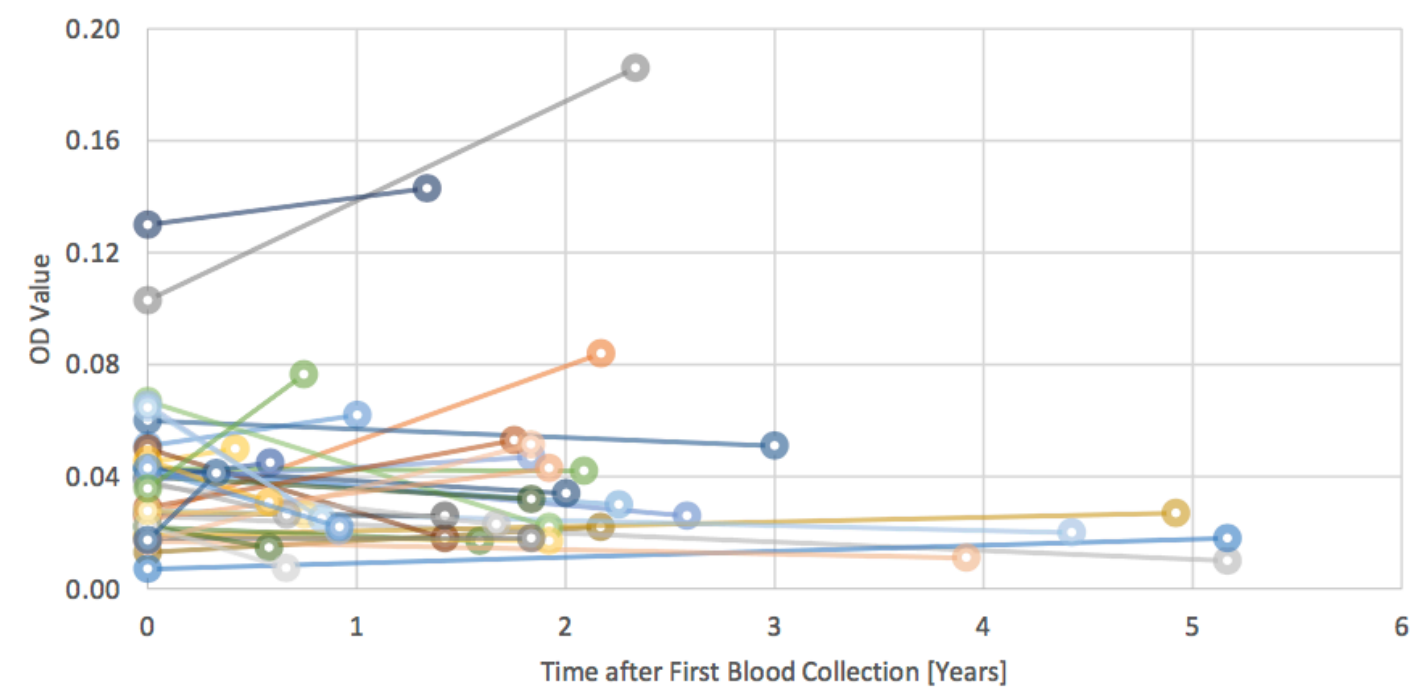


Figure 3

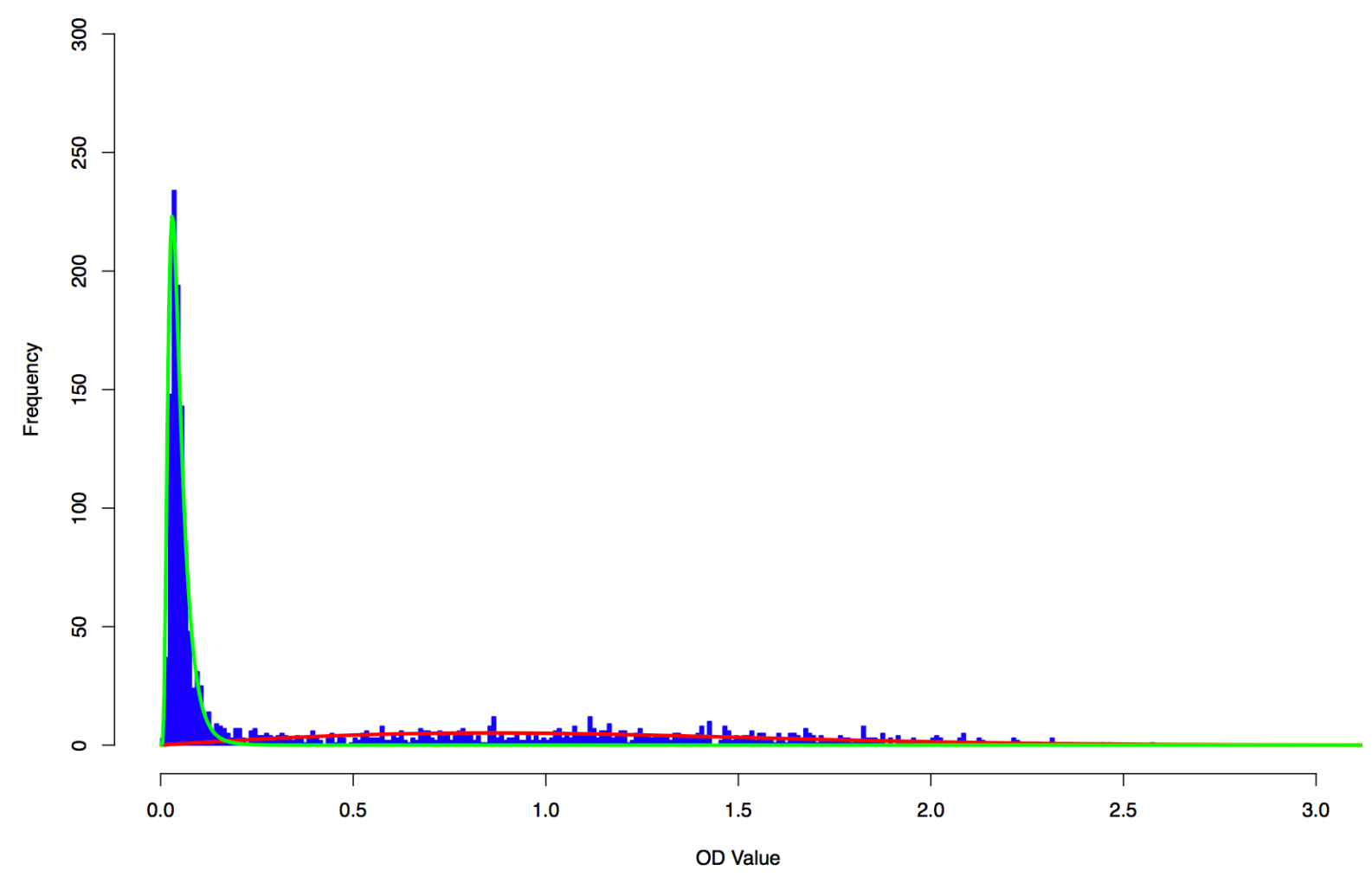

Figure 4

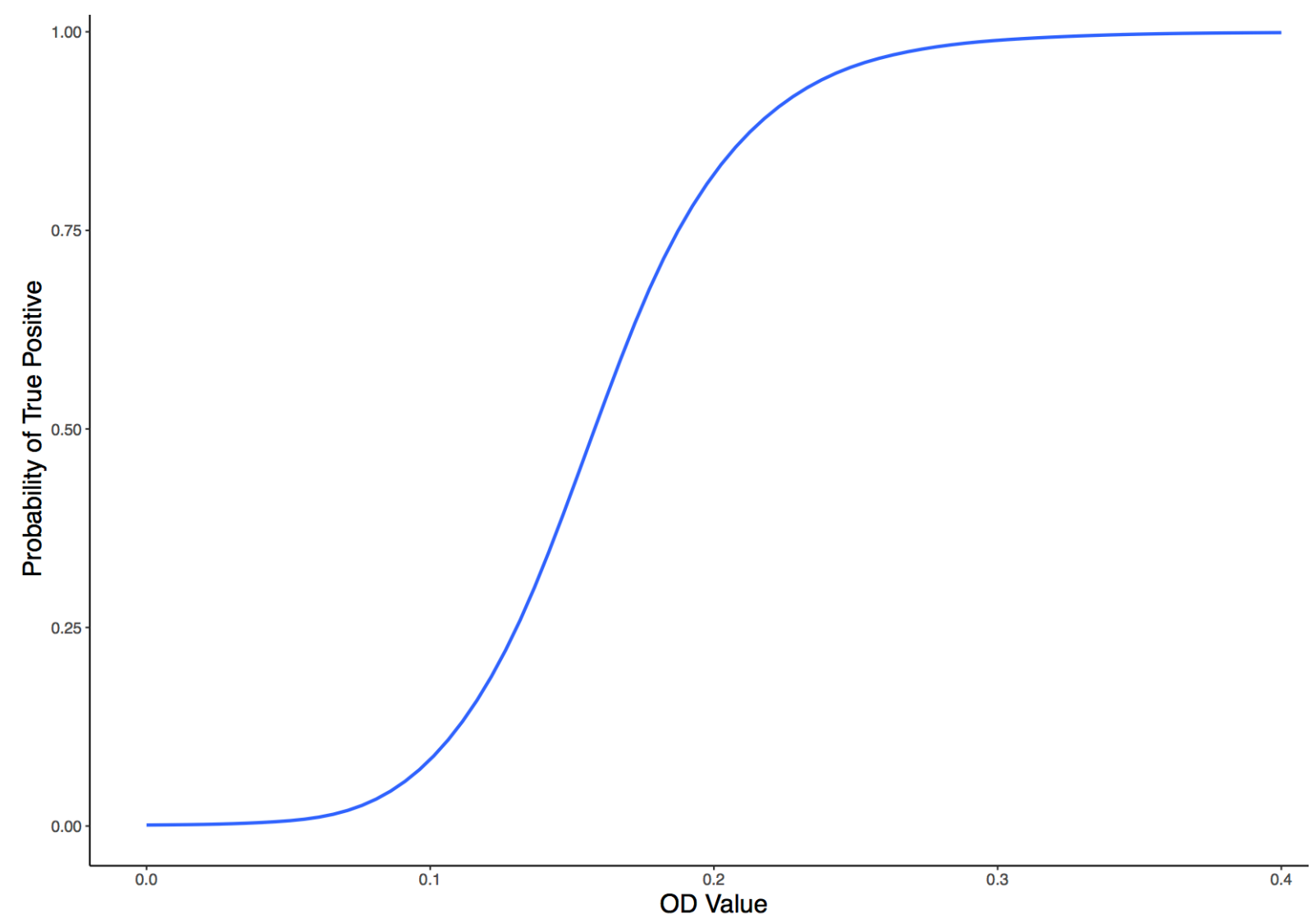


Figure 5

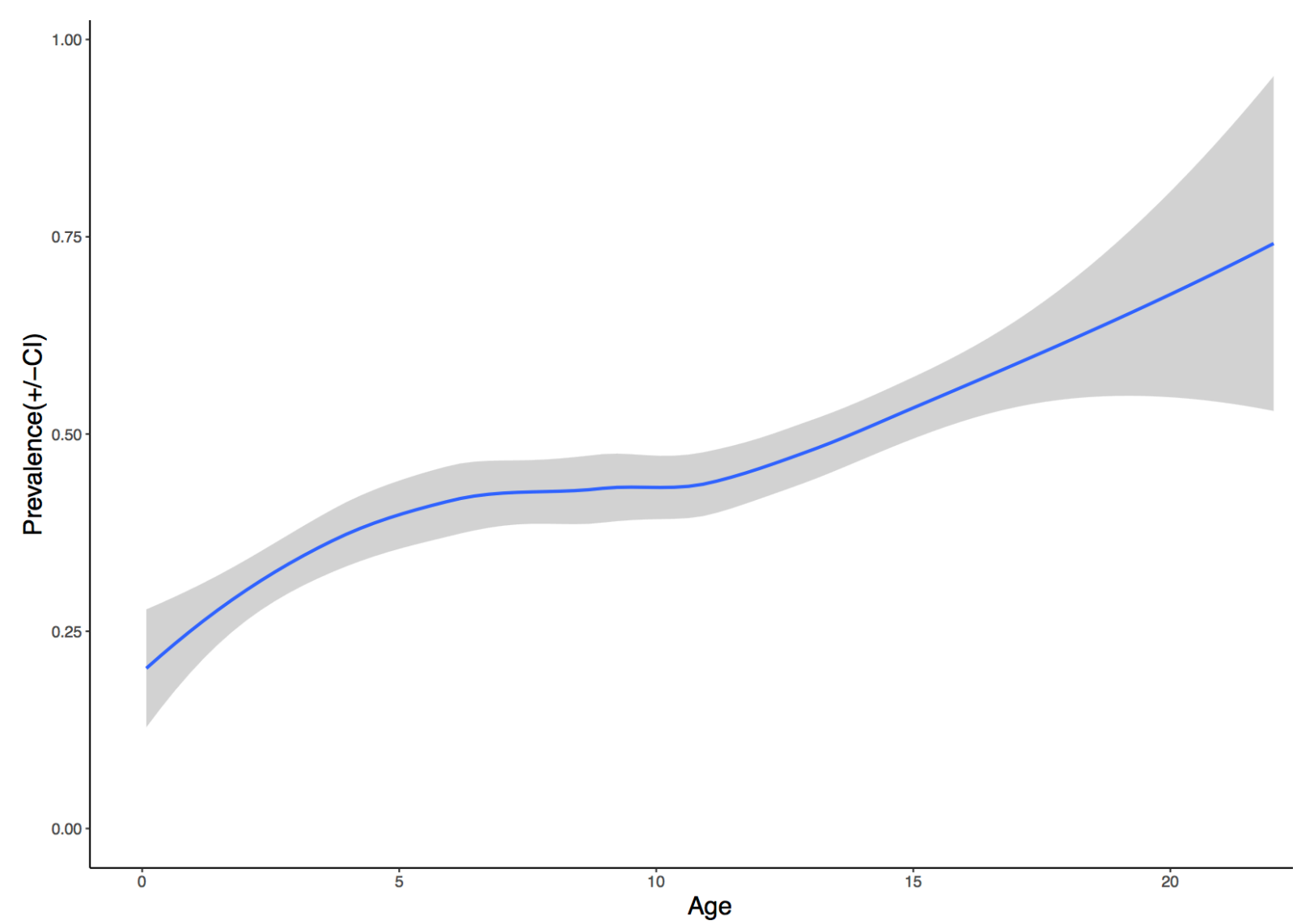




\section{Acknowledgements}

Thank you to my supervisors Peter Deplazes and Paul Torgerson for their support and guidance, the team of the institute of parasitology: Cristian Alavarez Rojas, Emily Güldner, Felix Grimm, Katharina Huggel, Annina Guggisberg, Camilla Stella, Stephanie Raymann, Michelle Bressan, Lea Rohner, Jeannine Fehr, the team of the Clinical Laboratory, Vetsuisse Faculty, University of Zurich, and all participating veterinarians: A.Balli, Ascona;

Kleintierpraxis und Petshop Adlergarten, Schattdorf UR; ANIMAL, Kleintierpraxis, Visp; Tierarztpraxis Calanda, Chur; Centro veterinario 3 Valli Sagl, Polleggio; Centro veterinario Preluna, Comano, Federica Leidi; Clinique veterinaire Dr. D. Stornetta et JB Deillon, Delement; Cabinet vétérinaire du Littoral S.A Dr. P. Sauve, Aubonne; Dres. Nägeli, Balerna; Tierarztpraxis Farnenbüel, Eschenbach SG; Tierklinik Rhenus, Flurlingen; Kleintierpraxis Obersee, Altendorf; Labor am Zugersee; Dr. F. Ardüser, Lenzerheide; Veterinaire-EcublensLausanne, Dr. J. Pfister; Praxis am Wyher, Küblis; Kleintierpraxis Stadler, Altdorf, and Tierklinik Appenzell, Dr. Fritsche, family and core team. 


\section{Curriculum Vitae}

First name Family name

Date of birth

Place of birth

Nationality

August/1999

- June/2005

September/2005 - June/2011

June/ 2011

August/ 2011

- July/2012

August/ 2012

- January/2018

December 2017

January / 2018

- October $/ 2020$

under the direction of

January / 2018

- April/2018
Prof. Dr. med. vet. Peter Deplazes

at the Institute of Parasitology

of the Vetsuisse Faculty University of Zurich

Director: Prof. Dr. med. vet. Peter Deplazes

Nora Schreiber
11.04 .1993
Frankfurt
German

Frankfurt International School

61440 Oberursel, Germany

Kaiserin Friedrich Gymnasium

61348 Bad Homburg, Germany

Abitur

Kaiserin Friedrich Gymnasium

61348 Bad Homburg, Germany

Studies in Biology

University of Zurich, 8006 Zurich, Switzerland

University of Zurich, 8006 Zurich, Switzerland

Veterinary medicine degree examination

University of Zurich, 8006 Zurich, Switzerland

\section{Doctoral Student}

at the Institute of Parasitology

University of Zurich, 8057 Zurich, Switzerland 
University of Zurich; 8057 Zurich, Switzerland

May /2018

Since May / 2019
- May /2019
Rotating Internship Cardiology

at the Clinic for Small Animal Internal Medicine

University of Zurich, 8057. Zurich, Switzerland

Residency Cardiology

at the Clinic for Small Animal Internal Medicine

University of Zurich, 8057 Zurich, Switzerland

Date and signature:

$$
5.11 .20
$$

Niselda 